\title{
A Spatially Explicit Approach for Sensitivity and Uncertainty Analysis of GIS-Multicriteria Landslide Susceptibility Mapping
}

\author{
Bakhtiar FEIZIZADEH ${ }^{1}$, Piotr JANKOWSKI ${ }^{2}$ and Thomas BLASCHKE ${ }^{1}$ \\ ${ }^{1}$ Dept. of Geoinformatics, University of Salzburg/Austria ·Bakhtiar.FeiziZadeh@stud.sbg.ac.at \\ ${ }^{2}$ Department of Geography, San Diego State University San Diego, CA/USA
}

This contribution was double-blind reviewed as full paper.

\begin{abstract}
GIS multicriteria decision analysis (MCDA) methods are increasingly being used in landslide susceptibility mapping for the prediction of future hazards, decision making, as well as hazard mitigation plans. However, the uncertainties associated with MCDA techniques are inevitable and model outcomes are prone to multiple types of uncertainty. In this paper, the spatiality explicitly method is employed to assess the uncertainty associated with two methods of GIS-MCDA namely, Analytical Hierarchical Process (AHP) and Ordered Weighted Averaging (OWA). Our methodology consists of three stages. The first-stage analysis makes use of the AHP matrix weights for GIS-MCDA based landslide susceptibility mapping. This phase is based on a multicriteria evaluation which assesses the susceptibility areas and the landslide hazard potentiality by considering causal and diagnostic criteria. In the second stage the sensitivity and uncertainty analysis of the AHP weights is performed using Monte Carlo Simulation (MCS) and Global Sensitive Analysis (GSA). Finally, validation of results was performed using the existing landslide inventory. This paper carried out a GIS-MCDA uncertainty analysis and demonstrates a solution for the uncertainty modelling. Through the validation exercise with known existing landslides, the AHP clearly performed best. Results of this research demonstrate that further improvement of the accuracy of GIS-based MCDA can be achieved by employing the spatiality explicitly method and accordingly applying MCS and GSA for sensitivity analysis of the AHP weights.
\end{abstract}

\section{Introduction}

GIS based Multicriteria Decision Analysis (MCDA) is primarily concerned with how to combine the information from several criteria to form a single index measuring the performance of many solution variants (CHEN et al. 2010). MCDA procedures utilize geographical data, consider the user's preferences, and combine preferences according to specified decision rules (MALCZEWSKI 2004; RAHMAN et al. 2012). The integration of MCDA techniques with GIS has considerably advanced the traditional data combination approaches for Landslide Susceptibility Mapping (LSM). However, GIS-MCDA based LSM

Jekel, T., Car, A., Strobl, J. \& Griesebner, G. (Eds.) (2013): GI_Forum 2013. Creating the GISociety. (c) Herbert Wichmann Verlag, VDE VERLAG GMBH, Berlin/Offenbach. ISBN 978-3-87907-532-4.

(C) ÖAW Verlag, Wien. eISBN 978-3-7001-7438-7, doi:10.1553/giscience2013s157. 
methods are often used without any indication of error or confidence in the results (FEIZIZADEH \& BLASCHKE 2013a). The uncertainties associated with MCDA techniques are inevitable and model outcomes are vulnerable to multiple types of uncertainty, including uncertainty in input data, structural uncertainties in the model and uncertainties in model parameters (ASCOUGH II et al. 2008). Such uncertainties may have significant impacts on the results, which may sometimes lead to inaccurate outcomes and undesirable consequences. In a decision-making context, if outcomes occur with probabilities, for which confidence intervals cannot be estimated, the decision-maker faces uncertainty (CHEN et al. 2011). Within the MCDA the uncertainty arises when the accuracy of spatial data is unknown (TENERELLI \& CARVER 2012). Therefore, MCDA models should be thoroughly evaluated to ensure their robustness under a wide range of possible conditions, where robustness is defined as a minimal response of model outcome to changing inputs (LIGMANN-ZIELINSKA \& JANKOWSKI 2012). A spatially explicit approach to uncertainty and sensitivity analysis has been suggested as an extension of the traditional non-spatial approach, which assumes homogeneity of weights in a MCDA model (LIGMANN-ZIELINSKA \& JANKOWSKI 2012). The LSM process developed in this research uses two wellestablished MCDA methods: Analytical Hierarchy Process (AHP) and Ordered Weighted Averaging (OWA) to arrive at two comparative spatial distributions of landslide susceptibility scores and then applies the spatial approach to uncertainty and sensitivity analysis to account for spatial variability criteria weights analysis, data combination and subsequently sensitive and uncertainty analysis using spatiality explicitly method.

\section{Study Area and Data}

The study area was the Tabriz basin, one of the sub-basins of the Urmia Lake, which is located in the north-west of Iran. The study area with $5378 \mathrm{~km}^{2}$ in size and about 2 million inhabitants is important for the East Azerbaijan province in terms of housing, industrial and agricultural activities. In order to develop a landslide susceptibility map of this area, we used nine evaluation criteria by considering the topographic, geological, climatic, and socioeconomic parameters, which were selected based on our previous researches in this area (see (FEIZIZADEH et al. 2013), and (FEIZIZADEH \& BLASCHKE 2013a) for strategy of criteria selection). In the data preparation phase, the topography maps at the scale of 1:25,000 were used to extract road and drainage maps. Respectively, these maps were used to obtain DEM, slope and aspect information. The lithology and fault maps were derived from geological maps at the scale of 1:100,000. A precipitation map was created using 30year meteorological data and the land use/cover map was derived from SPOT satellite images with spatial resolution $10 \mathrm{~m}$ based on image processing techniques. A necessary spatial data editing was done on the original datasets in order to create topologically correct layers. Finally, all vector layers were converted into raster format with $5 \mathrm{~m}$ resolution.

\section{Methods}

The research methodology is based on the concept of evaluating the uncertainty of GISMCDA for LSM through the spatially explicit method in order to: a) compare the accuracy of MCDA methods in light of simulated uncertainty of multiple criteria evaluation, and b) identify the effective method of GIS-MCDA for LSM. In order to achieve these objectives, 
the methodology is composed of three different phases. The first phase aims to rank the LSM criterion and to apply the AHP and OWA methods to produce the landslide susceptibility maps. This phase is based on multicriteria evaluation (MCE) which assesses the susceptibility areas and the landslide hazard potential by considering nine evaluation criteria. MCE methods allow multiple and often conflicting criteria to be taken into account and weights to be applied to input criteria depending on the level of importance ascribed to criteria by the user (TENERELLI \& CARVER 2012). The second phase involves sensitivity uncertainty analysis based on the spatially explicit simulation of error propagation. In this phase we employ Monte Carlo Simulation (MCS) to assess the uncertain weight space, where weights are expressed using Probability Density Functions (PDFs). The last phase considers the validation of results using the landslide inventory database and the landslide area were derived through object based image analysis procedure. In this phase we aim to compare the accuracy of the two approaches in LSM and investigate the improved accuracy under sensitive analysis.

\subsection{Assessing the criteria weights through AHP}

One of the most widely used methods in spatial multicriteria decision analysis is the analytic hierarchy process AHP, introduced and developed by SAATY (1977). As a multicriteria decision-making method, AHP is widely used as one of the major methods in solving a wide variety of problems that involve multiple criteria and where the interaction of criteria is common (SAATY 1977). GIS-based AHP has gained popularity because of its capacity to integrate a large quantity of heterogeneous data, and because obtaining the required weights can be relatively straightforward, even for a large number of criteria. It has been applied to a variety of decision-making problems (FEIZIZADEH et al. 2012). Since in any MCDA the weights are reflective of the relative importance of each criterion, they have to be carefully selected. A number of various weight estimation techniques have been developed for MCDA. Within this research we use a pairwise matrix to obtain criteria and sub-criteria weights based on the AHP technique (see table 1 as weights of criteria).

Table 1: Pairwise comparison matrix for dataset layers of landslide analysis

\begin{tabular}{|l|l|l|l|l|l|l|l|l|l|l|}
\hline Factors & $\mathbf{1}$ & $\mathbf{2}$ & $\mathbf{3}$ & $\mathbf{4}$ & $\mathbf{5}$ & $\mathbf{6}$ & $\mathbf{7}$ & $\mathbf{8}$ & $\mathbf{9}$ & $\begin{array}{l}\text { Eigen } \\
\text { Values }\end{array}$ \\
\hline (1) Aspect & 1 & & & & & & & & & 0.025 \\
\hline $\begin{array}{l}\text { (2) Distance to } \\
\text { road }\end{array}$ & $1 / 5$ & 1 & & & & & & & & 0.036 \\
\hline (3) Elevation & $1 / 2$ & $1 / 3$ & 1 & & & & & & & 0.020 \\
\hline $\begin{array}{l}\text { (4) Distance to } \\
\text { stream }\end{array}$ & $1 / 3$ & $1 / 3$ & $1 / 3$ & 1 & & & & & & 0.112 \\
\hline $\begin{array}{l}\text { (5) Distance to } \\
\text { fault }\end{array}$ & $1 / 3$ & $1 / 5$ & $1 / 5$ & $1 / 3$ & 1 & & & & & 0.124 \\
\hline (6) Slope & 7 & $1 / 5$ & 9 & $1 / 3$ & $1 / 4$ & 1 & & & 0.141 \\
\hline (7) Land use & 8 & 6 & $1 / 5$ & $1 / 5$ & $1 / 3$ & $1 / 3$ & 1 & & 0.160 \\
\hline (8) Precipitation & 8 & 6 & 7 & 7 & 4 & 3 & $1 / 5$ & 1 & 0.172 \\
\hline (9) lithology & 9 & 7 & $1 / 3$ & 8 & 7 & 4 & $1 / 5$ & 8 & 1 & 0.210 \\
\hline Consistency ratio: 0.053 & & & & & & & \\
\hline
\end{tabular}


Since human judgment can violate the transitivity rule and thus cause inconsistency, the consistency ratio (CR) is computed to check the consistency of the pairwise comparisons and further the consistency of computed weights (GORSEVSKI et al. 2006). Based on (SAATY 1977), if the CR $<0.10$, it stands to reason that the pairwise comparison matrix has an acceptable consistency and that the weight values are valid and can be accepted for multiple criteria evaluation. Otherwise, if the $\mathrm{CR} \geq 0.10$, this means that the pairwise comparisons are lacking consistency and the matrix needs to be adjusted and the element values should be modified (FEIZIZADEH \& BLASCHKE 2013b). In our research the CR value for pairwise matrix was 0.053 which shows the acceptable value of $\mathrm{CR}$.

\subsection{Implementation of AHP- Monte Carlo Simulation}

Simulation is one of the most appropriate approaches to analyse uncertainty propagation through a GIS model, without knowing the functional form of the errors (TENERELLI \& CARVER 2012). Since the uncertainties in data (attribute values) and in model parameters (weights) can be represented as probability distributions, analytical methods and sampling methods, such as the Monte Carlo method, could be applied. The Monte Carlo Simulation (MCS) technique is the most widely used statistical sampling method in uncertainty analysis of decision making system (CHEN et al. 2011). In our research we use the MCS to carry out the uncertainty associated with AHP weights. For this to happen our research methodology makes use of the concept of AHP-MCS where we simulate different realizations of criterion weights starting with the original set of weights obtained through the pairwise comparison. The AHP-MCS approach is based on sampling the vector of the original weights in a random sequence to get a corresponding statistical sample of the vector of weights, and then estimating the characteristics of these weights. This uses various standard statistical methods to estimate distributions of the output weights. This makes MCS a straightforward and powerful method to deal with sensitivity analysis and uncertainty propagation in complex models (ESPINOSA-PAREDES et al. 2012). We performed AHP-MCS to model the error propagation in the evaluation result according with the following steps:

I. Generate random dataset uniformly distributed using a random function

II. Use the AHP based criteria weights as reference weights

III. Repeat the simulation $\mathrm{N}$ times: the number of simulations $(\mathrm{N})$ varies from 100 to 10000 according to the computational load, the complexity of the model, and the desired accuracy

IV. Analyse the results and produce statistics, spatial distribution of the error including: the minimum rank, maximum rank, average rank and standard devotion rank.

\section{$4 \quad$ Landslide Susceptibility Mapping}

The results of MCDA-AHP and MCDA-AHP-MCS were used to perform LSM process. In order to better optimize, and quantitatively and qualitatively assess the results, in our research we employ a two-approaches analysis synergistically to form a spatial decision support system for LSM. The first-approaches analysis makes use of the GIS-MCDA to rank the LSM criterion and apply the AHP and OWA methods for producing the landslide susceptibility maps. In order to perform this approach the LSM criteria and sub-criteria are 
ranked based on AHP pairwise matrix (see Table 1). In the next step these criteria were combined and landslide susceptibility maps were created using OWA and AHP methods (see figure 1a and 1b). The first approach is based on the applying of conventional methodology of GIS-MCE for producing the base maps of GIS-MCE to utilize the advantage of comparison between the two approaches. In following of this objective the LSM methodology was established using the spatially explicit and GIS-MCDA-GSA in the second-approaches. In this approach, the landslide susceptibility maps were achieved by using the outcome of variance-based GSA. In doing so, the criteria were overlaid and the landslide susceptibility maps produced using OWA and AHP (see figure 1c and 1d). Finally all four landslide susceptibility maps were derived from both of the approaches and were classified into four groups, namely high, moderate, low and no susceptibility to landslides, using the natural breaks classification method.
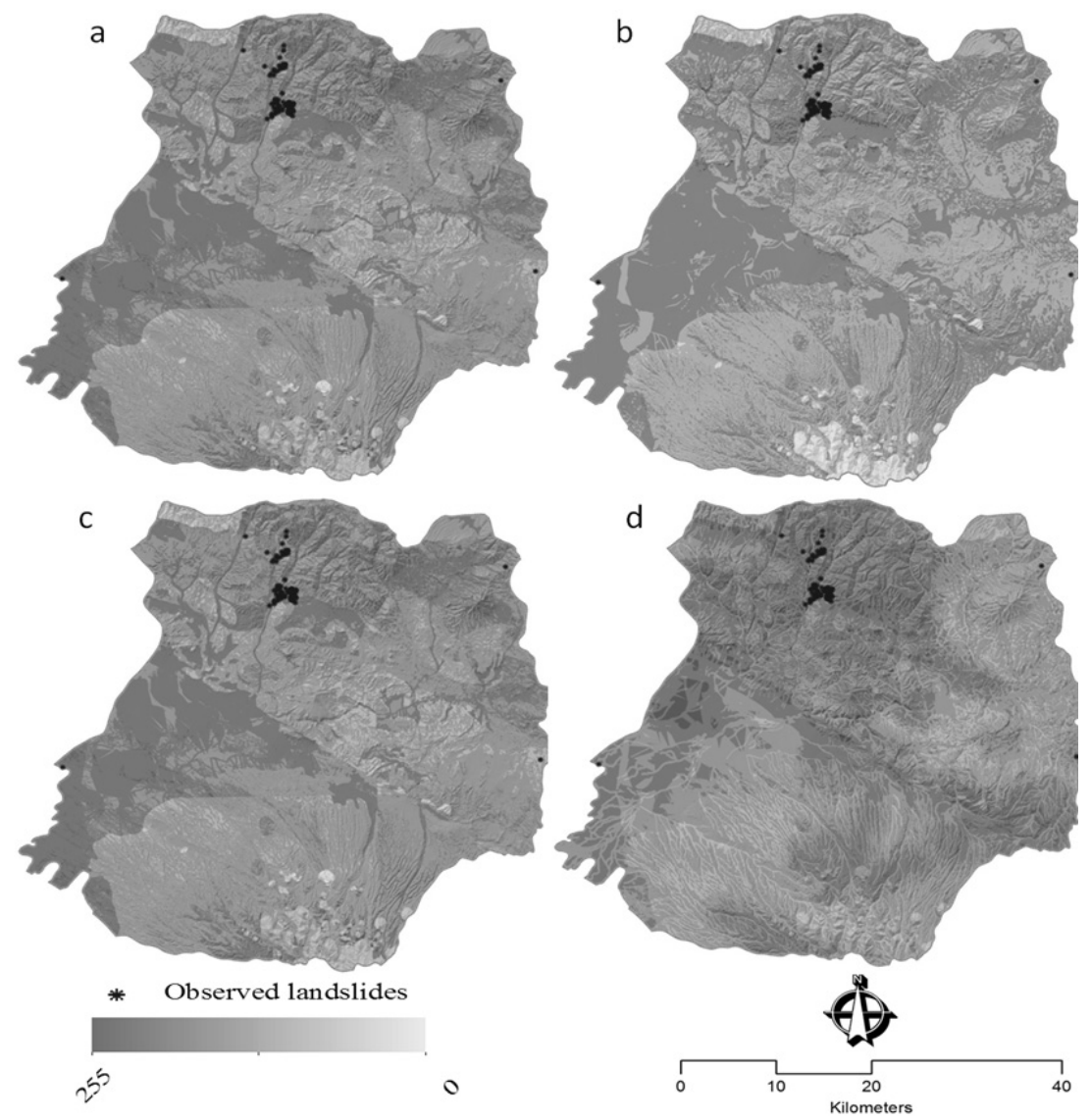

Fig. 1: Results of LSM: a) Landsides susceptibility map derived from GIS-MCE approach of OWA, b) Landslide susceptibility map derived from GIS-MCE approach of AHP; c) Landslide susceptibility map derived from second approach GSA- OWA, and d) Landslide susceptibility map derived from second approach GSA- AHP 


\subsection{Validation of results}

The obtained landslide susceptibility maps were evaluated by calculating Relative Operating Characteristics (ROC) and numbers of known landslides were observed in various categories of the landslide susceptibility maps. The ROC curve is a plot of the probability of having a true positive (correctly predicted event response) versus the probability of a false positive (falsely predicted event response) as the cut-off probability varies (GORSEVS$\mathrm{KI}$ et al. 2006). The landslide inventory database was used to perform a validation of results. The landslide database of the study area indicated the occurrence of 112 landslide events in Tabriz basin. We use the results of the delineated landslide from IRS-ID satellite images (with 5.8 meter spatial resolution) through the Object Based Image Analysis (OBIA) method which results from one of our early research activitues in this area (see BLASCHKE et al. 2013). Respectively the landslide areas (22.49 hectare) were used to assess the accuracy of results through the ROC curve. In the ROC curve the ideal model shows a value close to 1.0 (NANDI \& SHAKOOR 2009). In the context of cross-comparison between landslides currently occurring in the study area and the landslide susceptibility map derived from the OWA method (GIS-MCE approach), the ROC curve shows the reliability of about 0.15629 . While, in terms of the landslide susceptibility map obtained using the GSA- OWA method (GIS-MCDA-GSA approach), the ROC curve indicated the accuracy about 0.45565 . The ROC curve reveals the reliability of about 0.75415 while, with respect to assessing the reliability of the GSA-AHP, the ROC curve shows the reliability of about 0.90557. Table 2 shows the results of validation of landslide susceptibility maps. The number of existing landslide were identified in each category.

Table 2: $\quad$ Results of LSM and validation of results

\begin{tabular}{|c|c|c|c|c|c|}
\hline \multirow[t]{2}{*}{ MCDA } & \multirow[t]{2}{*}{$\begin{array}{c}\text { Susceptibility } \\
\text { category }\end{array}$} & \multicolumn{2}{|c|}{ GIS-MCE approach } & \multicolumn{2}{|c|}{$\begin{array}{c}\text { GIS-MCDA-GSA } \\
\text { approach }\end{array}$} \\
\hline & & observed landslide & Area $\mathbf{m}^{2}$ & $\begin{array}{l}\text { observed } \\
\text { landslide }\end{array}$ & Area $\mathrm{m}^{2}$ \\
\hline \multirow{5}{*}{ OWA } & $\begin{array}{c}\text { High } \\
\text { susceptibility }\end{array}$ & 3 & 1245 & 5 & 1675 \\
\hline & $\begin{array}{c}\text { Moderate } \\
\text { susceptibility }\end{array}$ & 33 & 74100 & 53 & 127925 \\
\hline & $\begin{array}{c}\text { Low } \\
\text { susceptibility }\end{array}$ & 76 & 149555 & 54 & 95300 \\
\hline & $\begin{array}{c}\text { No } \\
\text { susceptibility }\end{array}$ & - & - & - & - \\
\hline & Sum & 112 & 224900 & 112 & 224900 \\
\hline \multirow{5}{*}{ AHP } & $\begin{array}{c}\text { High } \\
\text { susceptibility }\end{array}$ & 20 & 44825 & 25 & 57200 \\
\hline & $\begin{array}{c}\text { Moderate } \\
\text { susceptibility }\end{array}$ & 81 & 190675 & 87 & 167700 \\
\hline & $\begin{array}{c}\text { Low } \\
\text { susceptibility }\end{array}$ & 11 & 10600 & '- & - \\
\hline & $\begin{array}{c}\text { No } \\
\text { susceptibility }\end{array}$ & - & - & - & - \\
\hline & Sum & 112 & 224900 & 112 & 224900 \\
\hline
\end{tabular}




\section{Conclusion and Future Work}

Combining GIS and MCDA is a powerful approach to LSM. Although a massive amount of papers on susceptibility models were published in the last two decades, only few of them have dealt with the evaluation of prediction capability, robustness, and sensitivity (MELCHIORRE et al. 2011). Due to the large amount of parameters and the heterogeneity of data sources, the uncertainty of the results is typically unclear. Even small changes in decision weights and methods may have a significant impact on the rank ordering of the criteria and may subsequently change the results (FEIZIZADEH \& BLASCHKE 2013a). The authors believe that for GIS-MCDA based LSM it becomes necessary to assess the reliability of the methods used. In this paper, we focused on the applying of spatially explicit approach for sensitive and uncertainty analysis of GIS-MCDA, integrating AHP and MCS for optimization algorithm and assessing the certainty of outcomes. As results indicated further improvement of the accuracy of GIS-based MCDA can be achieved by employing the spatially explicit method and accordingly integrating GSA for sensitivity analysis of the weights derived from AHP. This study demonstrates the importance of spatially explicit approach for incorporating GIS and MCDA models. Furthermore a result of this research pointed out it is possible to identify strategies and a methodology for LSM by assessing uncertainty of each method. We conclude that the information provided by these maps shall help citizens, planners and engineers to reduce losses caused by existing and future landslides by means of prevention, mitigation and avoidance. The results described in this article are therefore useful for explaining the driving factors of the known existing landslides, for supporting emergency decisions and for supporting the efforts on the mitigation of future landslide hazards in the Tabriz basin.

\section{References}

Ascough, J. C., Maier, H. R., Ravalico, J. K. \& Strudley, M. W. (2008), Future research challenges for incorporation of uncertainty in environmental and ecological decision-making, ecological modeling, 219, 383-399.

Blaschke, T., Feizizadeh, B. \& Hölbling, D. (2013), An object-based image analysis approach for landslide delineation in northern-west Iran, international journal of applied earth observation and geoinformation (under review).

Chen, M., Wood, M. D., Linstead, C. \& MAltBy, E. (2011), Uncertainty analysis in a GIS-based multi-criteria analysis tool for river catchment management. Environmental Modelling \& Software, 26, 395-405.

CHEN, Y., YU, J. \& KHAN, S. (2010), Spatial sensitivity analysis of multi-criteria weights in GIS-based land suitability evaluation. Environmental Modelling \& Software, 25 (12), 1582-1591.

Espinosa-Paredes, G., Polo-Labarrios, M. A. \& VÁzquez-Rodríguez, A. (2012), Sensitivity and uncertainty analysis of the Time-Fractional Telegrapher's Equation for neutron motion. Progress in Nuclear Energy, 61, 69-77.

FeizizadeH, B. \& BlaschKe, T. (2013a), GIS-Multicriteria Decision Analysis for Landslide Susceptibility Mapping: Comparing Three Methods for the Urmia Lake Basin, Iran. Natural Hazards, 65, 2105-2128. 
FeIZIZADEH, B. \& BlaschKe, T. (2013b), Land suitability analysis for Tabriz County, Iran: a multi-criteria evaluation approach using GIS. Journal Environmental Planning Management, 56, 1-23.

Feizizadeh, B., BlaschKe, T., NAzmFar, H. \& Rezaei Mogaddam, M. H. (2013), Landslide Susceptibility Mapping for the Urmia Lake basin, Iran: A multi- Criteria Evaluation Approach using GIS. International Journal of Environmental Research, 7 (2) 319336.

FEIzizadeh, B., BlaschKe, T. \& NAZMFaR, H. (2012), GIS-based Ordered Weighted Averaging and Dempster Shafer Methods for Landslide Susceptibility Mapping in Urmia lake Basin, Iran, International Journal of Digital Earth. DOI:10.1080/17538947.2012.749950.

Gorsevski, P. V., Gessler, P. E., Foltz, R. B. \& Elliot, W. J. (2006), Spatial prediction of landslide hazard using logistic regression and ROC analysis. Transactions in GIS 10, 395-415.

LIGMANN-ZIELINSKA, A. \& JANKOWSKI, P. (2012), Impact of proximity-adjusted preferences on rank-order stability in geographical multicriteria decision analysis. Journal of Geographical Systems, 14, 167-187.

Melchiorre, C., Castellanos Abella, E. A., van Westen, C. J \& Matteucci, M. (2011), Evaluation of prediction capability, robustness, and sensitivity in non-linear landslide susceptibility models, Guanta namo, Cuba. Computers \& Geosciences, 37, 410-425.

MALCZEWSKI, J. (2004), GIS-based land-use suitability analysis: a critical overview. Progress in Planning, 62 (1), 3-65.

Rahman, M. A., Rusteberg, B., Gogu, R. C., Lobo Ferreira, J. P. \& Sauter, M. (2012), A new spatial multi-criteria decision support tool for site selection for implementation of managed aquifer recharge. Journal of Environmental Management, 99, 61-75.

RAMI MAHMOUD, M. R. \& GARCIA, L. R. (2000), Comparison of different multicriteria evaluation methods for the Red Bluff diversion dam. Environmental Modelling \& Software, 15, 471-478.

SAATY, T. L. (1977), A scaling method for priorities in hierarchical structure. Journal of Mathematical Psychology, 15 (3), 234-281.

TENERELLI, P. \& CARVER, S. (2012), Multi-criteria, multi-objective and uncertainty analysis for agro-energy spatial modeling. Applied Geography, 32, 724-736. 